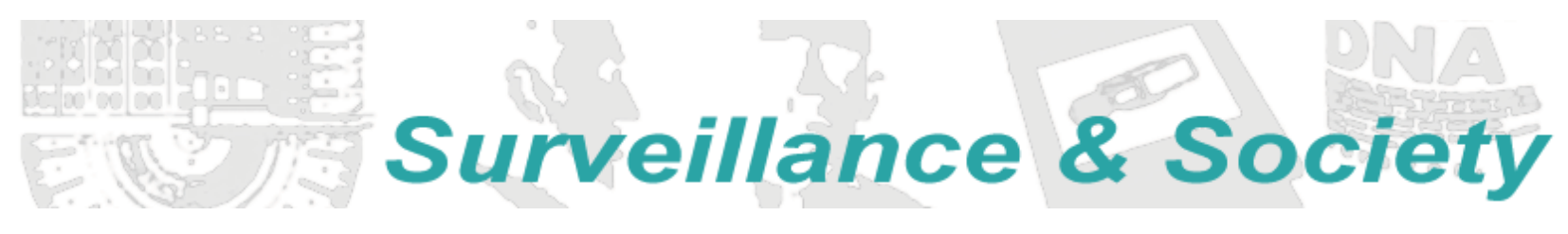

\title{
Article | Monitoring in Youth Sport: A Paradigm Shift
}

\section{Elaine Cook}

University of Toronto, Canada. cookelaine@bell.net

\section{Kim D. Dorsch}

University of Regina, Canada. kim.dorsch@uregina.ca

\begin{abstract}
Research indicates that the culture of sport tends to promote mythologized perceptions of the benefits of participation for youth (Giulianotti 2004). However, a growing body of literature suggests (e.g., Brackenridge 2007; David 2005; Raakman, Dorsch and Rhind 2010a) that negative, potentially abusive, coaching behaviours may be prevalent in the youth sport system. Estimation of the problem and resultant policy development has been hindered by the lack of adequate surveillance of these behaviours in these contexts. It is the purpose of this study to propose that positive surveillance is both necessary and beneficial for youth sports. To accomplish these aims the authors examine both: (a) the extent of negative coaching behaviours in four youth sports; and (b) the utility of an online system of behavioural management (i.e. monitoring). For this study three independent raters collectively identified 256 behaviours from 164 comments made by officials in four different sports (ice hockey, baseball, football, and basketball). The behaviours were then deductively analyzed and categorized using the Typology of Coaching Transgressions (TOCT) model (Raakman et al. 2010a). The original data were collected by the Justplay Behaviour Management Program (JPBMP). Results indicate that across all sports 77 per cent of all harmful coaching behaviours are indirect in nature. Additionally, across all sports the psychological (38 per cent) and modelling categories (27 per cent) contain the greatest percentage of harmful behaviours. The two contact sports contained the greatest number of direct and neglectful behaviours. Discussion revolves around the importance of providing data through surveillance and monitoring, to facilitate the development of policies regarding coaching behaviours, and also the utility of the TOCT model in the identification of negative coaching behaviours.
\end{abstract}

Personal information now travels at hitherto unimaginable rates between organizations, due in large part to the internet (Lyon 2007). While internet surveillance enables organizations to breakdown and classify information through digital assemblages (Sluggett 2011) to increase the transparency of individual lives and reduce privacy, it also empowers sports governing bodies by giving them access to more information they can use to control individuals and groups (Lang 2010; Fusco 2009). In fact, it has been suggested that surveillance, defined as 'watching over' (Lyon 2007: 444) is now an accepted, if not controversial, means of contemporary sports governance (Lyon 2007). It should therefore not be surprising that the concept of surveillance is becoming widely debated in contemporary sport (Fusco 2009; Johns and Johns 2000; Lang 2010) as the general awareness of how technology aids in the collection, use, and sharing of personal information increases.

Literature examining surveillance in sport indicates how personal information is used as: (a) a means to exert control over athletes' bodies and enhance compliance of athletes to the norms of sport (Chapman 1997; Lang 2010; Maguire and Mansfield 1998); (b) a Foucauldian perspective that describes the monitoring and evaluation policies of elite national multi-sport training centres (Fusco 2009); or (c) antidoping assemblages (Sluggett 2011). While these concerns invite a useful and necessary discourse about the power and abuses of sports governance, at least some of the concerns associated with surveillance in sport provide support for the monitoring of coaches, athletes and other official personnel. As such, this 
paper aims to provide persuasive evidence, as well as suggestions for appropriate monitoring procedures that encourage sports governance aims proposed by Schon (as cited in Parsons 2002) that seek to facilitate the self-management and individualized transformation and growth of individuals, organizations, and communities.

Although monitoring and evaluation are considered integral elements to policy development and analysis (Dunn 2008), it is generally accepted that there has been a historical and detrimental lack of positive surveillance in the sport context (Brackenridge, Kay and Rhind 2012; David 2005; UNICEF 2010). It has been suggested that this is due in part to policy paradigms created in the sport environment. A policy paradigm is described as 'an overarching framework of ideas that structures policy making in a particular field' (Hall 1990: 59). These paradigms are also referred to as 'storylines' (Fischer 2003), and it has been suggested that they control policy development because they influence what is or is not measured and how (McGee and Brock 2001). Importantly, storylines are seldom publicly or privately questioned (Stone, Maxwell and Keating 2001), probably because they are seen as truths. This is particularly true in sport, as carefully crafted beliefs that shape the culture of sport often dissuade critical assessment of contentious governance practices. In essence, sport has been mythologized as a haven for positivity and moral character building (Brackenridge 2006).

Although policy monitoring is more often than not conjoined with evaluation, the latter is a separate function. Monitoring measures something positive, such as progress, trends, or results, while evaluation provides a more detailed examination of the impacts and outcomes (Kusek and Rist 2008). Monitoring helps to establish quantitative measures or indicators, which subsequently provide the means to establish progress of outcomes, as well as the effectiveness of policies (Pintér, Swanson and Barr 2004). Similarly, Cohen (1999) states that monitoring is about setting regulations, policies, compliance and enforcement strategies, as well as measurement of their effectiveness to assess their net benefits. The results of monitoring are evaluated in order to generate information that informs policy makers (Dunn 2008; Stone, Maxwell and Keating 2001), and, with any luck, storylines. Thus, there is a strong and essential relationship between monitoring and the first phase of policy development-problem definition (Brackenridge, Bringer and Bishopp 2005; Dunn 2008; Kusek and Rist 2008; Stone, Maxwell and Keating 2001). Consequently, policies (particularly ones revolving around behavioural conduct) are developed around those issues which are deemed crucial or identified as problematic. However, if policy makers don't believe there is a problem, or do not have evidence to suggest there is one, then there is little impetus to generate policy. Alternatively, policy may be developed but poorly implemented or enforced, as was clearly revealed in Brackenridge's (2004) evaluation of SportScotland's implementation of mandatory child protection policies.

Sport is often excluded from normative social and legal standards due to its perceived exceptionalism (Giulianotti 2004), its inspirational role (Houlihan, Bloyce and Smith 2011), and its portrayal as a moral oasis (Brackenridge 2006). This is particularly so in youth sport, where the mythologized cultural myths that surround sport often render sports governing bodies immune from regular monitoring, evaluation, and accountability (Brackenridge 2006; Forster 2006). Some experts suggest that these myths perpetuate the power and autonomy of global sport organizations, which in turn, contributes to the lack of policy development and incentive to adopt a culture of rights for the youth sport participant (Coalter 2007; Forster 2006; Giulianotti 2004).

The research within the youth sport domain indicates that a tension exists between the positive (e.g., Barnett, Smoll and Smith 1992; Gibbons, Ebbeck and Weiss 1995; Gould and Carson 2008) and negative outcomes (Bolter 2010; Brackenridge 2007; David 2005) for children who participate in youth sports. As a result, there has been increasing pressure from researchers directed at sport governing bodies to respond with policies and tools that safeguard the human rights of child and youth participants (Brackenridge 2012; Malkin, Johnston and Brackenridge 2000; Turner and McCrory 2004). There is also a general 
consensus amongst researchers that not enough research is being done with regard to the study of violence and harmful coaching practices in youth sports (Brackenridge, Kay and Rhind 2012; David 2005; UNICEF 2010; Stirling and Kerr 2007; Telfer 2012).

It is well accepted that coaches are the most influential people with respect to children's experiences in youth sport (Gervis 2012; McCallister, Binde and Weiss 2000; Steelman 1995; Telfer 2012). At the same time, evidence suggests that: (a) the coach's philosophy is often inconsistent with their behaviour (Dorsch, Riemer, Zimmer and Karreman 2009; McCallister et al. 2000); (b) that poor coach behaviour is correlated with anti-social behaviour of youth sport participants (Rutten et al. 2007); and (c) current education models do little to provide coaches with an understanding of the impact their behaviours have on the experiences and outcomes of children and youth (Abraham, Collins and Martindale 2006; Telfer 2012). Couple this knowledge with recent research indicating that abusive coaching behaviours are normalized and legitimized by certain sport cultures (Bolter 2010; Gervis 2010; Gervis and Dunn 2004; Stirling 2008; Stirling and Kerr 2007; Walters, Schluter, Thomson and Payne 2011), and it becomes evident that a consistent, objective monitoring programme is required to identify and quantify negative coaching behaviours in youth sport. Indeed, this issue is important to rectify through clear sport policy development.

Although there is recognition among researchers and experts for an internationally recognized code of conduct/policy framework to help govern and direct coaching behaviour (Brackenridge 2007; David 2005; Duffy 2010; ICCE 2010), for the most part the mythology of sport has dampened any critical assessment of youth sport policy. Indeed, Patrick Duffy, Vice President of the International Council of Coach Education (ICCE), has suggested: '(it) may then be necessary to formulate specific codes of conduct that make explicit the behaviours which are and are not acceptable in given coaching roles' (2010: 14). Further, a significant portion of the research regarding unacceptable coaching behaviours in youth sport has focused on sexual abuse (Brackenridge 2006, 2007; Stirling 2008) or has been approached from a coaching efficacy perspective (Baker, Yardley and Côté 2003; Fung 2003; Mallett and Côté 2006; Smith, Smoll and Cumming 2007). There is also is an intense focus on the outcomes associated with elite child athletes (Brackenridge and Rhind 2010; Fasting, Brackenridge and Sundgot-Borgen 2004; Weber 2009), who represent a minute percentage of those who participate in youth sports. In his seminal book, Human Rights in Youth Sports: A Critical Review of Children's Rights in Competitive Sports, Paulo David (2005) estimates that approximately 10 per cent of all children participating in youth sport have been subjected to some form of physical, psychological, sexual, or neglectful abuse throughout their years of participation.

To identify unacceptable coaching behaviours in non-elite, recreational sports, the Typology of Coaching Transgressions model (TOCT) was developed by Raakman, Dorsch and Rhind (2010a). Through an examination of comments provided by officials within the sports of ice hockey and soccer and based upon the work of David (2005), Raakman et al. (2010a) identified two general categories of abuse: direct and indirect (see Table 1). Direct abuse was defined as any behaviour of the coach aimed directly at or involving a player(s) that violates the child in the following categories: physical, sexual, psychological, neglectful, or inappropriate modelling. The second category, indirect abuse, was defined as any behaviour of the coach directed at any participant within the context of the event that takes place in the presence of the player(s) and may violate their rights in the following categories: physical, sexual, psychological, neglect, or inappropriate modelling. The latter category was deemed important to add based on the knowledge about the negative effects of background anger (Omli and LaVoi 2009) upon the psychological and physiological responses of children. Omli and LaVoi explain that background anger, which is defined as the presence of verbal, nonverbal, or physical conflict between two or more individuals that children witness as bystanders, pervades family (Cummings 1987). Because research indicates that much reported abuse in youth sport takes place between adults and is witnessed by children (Shields, Bredemeier, LaVoi and Power 2005; Shields, LaVoi, Bredemeier and Power 2007), it is thought that youth sport events are a prime source of exposure to background anger. 


\begin{tabular}{|c|c|}
\hline Type of Coaching Transgression & Examples \\
\hline Direct physical harm & $\begin{array}{l}\text { - justification of player's behaviour } \\
\text { - reinforcing injurious behaviour } \\
\text { - encouraging fighting or physical behaviour }\end{array}$ \\
\hline Direct psychological harm & $\begin{array}{l}\text { - yelling/swearing at players } \\
\text { - demoralization } \\
\text { - running up the score } \\
\text { - justifying racial slurs } \\
\text { - taunting fans } \\
\text { - threatening own player }\end{array}$ \\
\hline Direct neglect & $\begin{array}{l}\text { - lack of discipline/control } \\
\text { - lack of care }\end{array}$ \\
\hline Direct modelling behaviours & - deliberate breaking of rules using players \\
\hline Indirect physical harm & $\begin{array}{l}\text { - involvement in physical behaviours } \\
\text { - throwing objects at officials } \\
\text { - threatening behaviour }\end{array}$ \\
\hline Indirect psychological harm & $\begin{array}{l}\text { - harassment of officials } \\
\text { - yelling at others } \\
\text { - challenging calls } \\
\text { - abusive behaviour } \\
\text { - foul language/emotional displays } \\
\text { - removal from game } \\
\text { - intimidation }\end{array}$ \\
\hline Indirect Neglect & - insinuating a player is not injured \\
\hline Indirect modelling behaviours & $\begin{array}{l}\text { - penalization of coach } \\
\text { - disrespect of officials, game, and opponents } \\
\text { - general negative behaviour/poor sportsmanship } \\
\text { - lack of rule knowledge }\end{array}$ \\
\hline
\end{tabular}

Table 1: Typology of Coaching Transgressions: Higher and Lower Order Themes

The work of the Child Protection in Sport Unit (CPSU) ${ }^{1}$ includes countering sexual, emotional, physical, and neglectful abuse, while also targeting bullying and poor practice (Brackenridge, Bringer and Bishopp 2005). Within the TOCT model, poor practice would fall generally under the modelling category, while specific bullying behaviours would be categorized under any one of the five major categories. It is fairly evident that despite the exclusion of indirect coaching abuses by the CPSU model, the two typologies of negative coaching behaviour are similar. Thus, the external validity of the TOCT model increases with the coherence of various sources (Patton 2001). Unfortunately, the CPSU and their partner sport-governing bodies have been unable to develop or discover a reliable, simple and effective monitoring system in order to further support their model.

The TOCT model (Raakman et al. 2010a) provides a framework within which potential harmful coaching behaviours can be classified, thereby providing a system for evaluating data collected by monitoring coaching activity. Brackenridge and Fasting assert that typologies have educational value because they

${ }^{1}$ The CPSU is a federally supported programme in the United Kingdom responsible for policy development (CPSU 2003) and a contributor to the International Safety Standards for Children in Sport (Beyond Sport Summit 2012). 
alert us to behaviours that might otherwise escape our attention, as 'we know relatively little about the characteristics of the harassing coach' (2009: 22). Therefore, the typology can be used, as Brackenridge and Fasting suggest, as a pedagogic tool that facilitates the investigation of harmful coaching behaviours, and allows the re-scripting of inappropriate behaviours. Furthermore, by classifying coaching transgressions, researchers and youth sport administrators can have a better understanding of systemic policy weaknesses, which enables the development of more strategic and effective responses to identified problems. Additionally the model assists understanding of the types of abuse to which children are exposed, as well as their prevalence, which is particularly important because 'only when the prevalence of a problem becomes important does population-based surveillance become important' (Biglan, Mrazek, Carnine and Flay 2003: 434). In other words, until there is sufficient data to suggest the problem requires prioritization, communities and sport governing bodies will not be concerned with formulating policies to support prevention. Similarly, without the monitoring of prevalence, preventative programmes will not improve or will remain ineffective (LaPorte, Kohl, Dearwater, Kriska, Anderson, Aaron, and McCarty 1993). Previous research using the TOCT model by Raakman and colleagues (2010a, 2010b) has identified that approximately 40 per cent of youth ice hockey, 37 per cent of youth football, and 36 per cent of youth baseball games contain negative coaching behaviours, with the majority of these involving indirect psychological harm. These numbers indicate a prevalence far exceeding the 'few bad apples' storyline of abusive coaching in youth sport. Yet the normalization of these types of behaviours makes them difficult to identify as potentially harmful. For instance, the following comment is an example of indirect psychological harm from one ice hockey association, and illustrates behaviours that are pervasive in youth sport: 'Head coach was taunting fans and screaming obscenities loudly in the rink'.

Recognizing that the storylines of youth sport are not all of an exceptional or inspirational nature is a first step to ensuring positive sporting experiences for young people. The second step to developing meaningful prevention and intervention strategies designed to educate and support leadership development is to identify, quantify, and classify the behaviours that detract from the positive storyline, using data collected from a reliable monitoring tool. As such, this study uses the TOCT model to quantify and describe negative coaching behaviours, or key indicators, for further evaluation in youth sport, and to simultaneously demonstrate the critical value of the Justplay Behaviour Management Program (JPBMP) as a monitoring tool. We are in fact, utilizing an existing surveillance system to provide the data for the monitoring tool, the official. The officials are required by law to 'watch over' the game environment.

\section{Methodology}

The methodology of this study is consistent with an ethnographic approach (Whitehead 2005), and as such, is interpretive, reflexive, and constructivist with regards to the epistemological and ontological orientations. Specifically, this study uses Whitehead's (2005) cultural systems paradigm (CSP), which promotes a holistic study of the culture in question, based on the principles of: (a) universal human cultural categories; (b) interindividual and intergroup variations in expression; (c) paradigmatic flexibility; (d) interrelationships between socio-cultural contexts, processes, and meaning systems; and (e) holism in meaning systems. In particular, the CSP allows for examination of individual and shared behaviour patterns, as well as idea systems (knowledge, attitudes, beliefs, and values) held by individuals and groups. Using the CSP approach allows for the investigation of patterns of coaching behaviours across various sports and their cultures, as well as those patterns that consistently emerge across all sports, while allowing for flexibility of the conceptual model (TOCT model). Finally, it encourages a greater understanding of the social and cultural contexts under investigation, which in turn can better inform knowledge claims (Sandberg 2005). These are important elements not only for monitoring coaching practices in terms of prevalence, but they are also important in the evaluation of sport policies, since qualitative measures provide a more complete understanding of the problems (Stem, Margoluis, Salafsky and Brown 2005). 
In 2001, Raakman (2006) designed a tool to monitor the behaviours of coaches, players, spectators, and officials in team sport environments. The JPBMP, involves the sport official as an observer providing data about the game environment on a game-by-game basis. As such, the official is viewed as part of the ethnographic team, embedded in the field as participant observer, contextual expert and member of the culture, which increases the emic validity of the data. ${ }^{2}$ Emic validity is further enhanced by the repetitive, iterative observations that are collected from the officials on a game-by-game basis throughout the season. The official observations are reflective, made post-game, allowing the official to concentrate on their surveillance role for the duration of the game. The observations are completely subjective, independent, and unique to each individual and sport organization, thus meeting the parameters of two CSP principles, which state that it is important to understand the social and cultural context in order to understand the behaviours associated with that context and maintain a flexible framework. Consequently, a secondary analysis of data collected by the JPBMP was conducted. The remainder of this section will describe the JPBMP in more detail, as well as, the procedures associated with data analysis.

\section{Instrumentation}

As stated previously, the JPBMP collects and assesses data input from the game official. Due to the unique contribution and legally required presence of game officials, they are considered the most appropriate and ethical source of monitoring data for many reasons. In particular: (a) their role is to ensure that the game is played as fairly as possible; (b) they are the only participant group with no stake in the outcome of the game; (c) they are the only participant group that is systematically accountable for their level of expertise; (d) they are paid for their impartiality and independent services; and (e) their presence contributes to the safety of the participants. For these reasons the JPBMP enlists the officials to independently monitor the conduct/behaviour of participant groups, thereby providing a previously unrecognized form of surveillance.

Upon registration in the JPBMP system, officials are made aware that the data they provide is the property of the JPBMP and may be used for research purposes. Following every game, each participating official, regardless of their role (linesman, head referee, etc.) independently fills out a Justplay Conduct Report Card (JPRC). Depending on the sport, there can be as few as one card per game, or as many as represented by the total number of officials involved in the game (e.g. one to three officials per ice hockey game). Official compliance rates (the percentage of officials reporting) are computed based on the number of cards submitted as compared to the number of cards available per game.

The official uses the JPRC to keep track of ratings for the overall behaviour of coaches, players, and spectators of the home and visiting teams on a 1 Very Good to 5 Very Poor Likert scale. Officials can then enter the ratings on their card into the JPBMP database via a password protected website. Officials are also provided with a space to write comments that help to elucidate their observations. Ratings of 4 Poor and 5 Very Poor are identified as critical incidents. For the purposes of this study, only cards containing comments that identify poor or very poor coaching conduct were considered because it is only the negative and potentially harmful behaviours that are of interest in terms of classification.

\section{Sample}

For the purposes of this study, a purposive sample of football, baseball, basketball, and ice hockey data was extracted from the JPBMP database. Organizations selected for this study have comparable age divisions and skill levels (leagues). Additionally, each of the selected organizations represent centres of varying demographic size and geography. For example, baseball is from a small town $(<20,000)$, football

2 '[T]he opportunity for repetitive, iterative, and situational observations that are culturally and intrinsically distinct and meaningful to the members of a given society' (Whitehead 2005: 5; Lett 2012). 
$(\sim 700,000)$ and basketball $(>1,000,000)$ from large urban centres, and ice hockey heralds from a moderately sized centre $(<200,000)$. The baseball, football, and ice hockey associations are from central Canada, while the basketball association is located in western Canada. Each of the selected organizations includes participants ranging from 8 to 17 years old. For privacy reasons JPBMP does not collect any personal data regarding coaches.

The utility of the JPBMP depends upon the compliance of the officials in completing the cards. Compliance is calculated by dividing the total number of cards available to officials by the actual number of cards filled out by officials. Every game has a number of cards available dependent upon the number of officials assigned to the game.

\section{Data}

Data for this study were extracted from the JPBMP database for two ice hockey associations (hockey association $A$, and hockey association $B$ ), one basketball association, one baseball association, and one youth football association. Hockey association A had 46 comments, with a general compliance rate of 100 per cent, while hockey association B had 42 comments, with a general compliance rate of 40 per cent. The basketball association had 57 comments over two seasons with compliance rates ranging from 9 to 18 per cent. The football association had 20 comments from three seasons with compliance rates ranging from 19 to 86 per cent. Finally the baseball association had just 8 comments from two seasons with 86 per cent compliance in each season. A total of 164 comments from these four sports were examined.

\section{Procedure}

Following approval for a secondary analysis of data by the university's research ethics board, the researcher deductively analyzed the 164 official comments concerning inappropriate coaching behaviours using the discreet higher and lower order categories of the TOCT model (Raakman et al. 2010a). In addition, two independent raters were asked to identify and classify all behaviours to enhance credibility and validity of the TOCT model.

The two independent raters were sent instructions that included the behaviour definitions of the TOCT model (see Table 1) and spreadsheets with each of the 164 officials' comments on separate lines. The raters were asked to complete the data analysis in three steps: (a) to first extract the behaviours from each comment; (b) to then classify each behaviour as either Direct or Indirect; and (c) to then classify each behaviour into one of the following subcategories included in the TOCT model (i.e. physical, sexual, psychological, neglect, or modelling). Raters were asked to identify and classify about 10 per cent of the comments on each page, at which point a meeting was held to review instructions, discuss problems, and provide clarifications.

A test of inter-rater reliability (IRR) was assessed using a mixed, agreement, average-measures intraclass correlation (ICC; Hallgren 2012) to assess the degree to which raters had absolute agreement with respect to the identification of behaviours according to the TOCT model definitions. The resulting ICC was in the excellent range, $I C C=1.00$, indicating that coders had a very high degree of agreement and identified behaviours in all sports similarly. An IRR analysis to assess the degree that the coders agreed absolutely on the categorical ratings of each behaviour as direct or indirect was then conducted. Kappa was computed for each rater pair then averaged to provide a single index of IRR (Light 1971). The resulting kappa, $\kappa=$ .965 , indicates excellent agreement between raters with regard to the categorization of behaviours into the higher order direct and indirect themes. Finally, an interclass correlation was also performed to assess the degree of agreement between the raters for the categorization of behaviours into the lower order psychological, physical, neglect, modelling, and sexual abuse themes. The IRR was assessed as a mixed, agreement, average measures ICC. The resulting ICC was also in the excellent range, ICC $=.989$, 
indicating the raters had a very high degree of agreement and categorized behaviours similarly into the lower order theme categories.

\section{Results}

In total, 255 behaviours were identified from the 164 comments. Table 2 presents a summary of the classification of behaviours by sport.

\begin{tabular}{llllll}
\hline & Hock ey & Basketball & Football & Baseball & $\mathrm{N}$ \\
\hline Comments & 85 & 51 & 20 & 8 & 164 \\
Behaviours & 133 & 80 & 33 & 9 & 255 \\
Indirect & 102 & 71 & 18 & 8 & 199 \\
Direct & 32 & 9 & 15 & 0 & 56 \\
Psychological & $57(43 \%)$ & $38(48 \%)$ & $13(39 \%)$ & $2(22 \%)$ & 111 \\
Modeling & $57(43 \%)$ & $36(45 \%)$ & $14(42 \%)$ & $6(42 \%)$ & 114 \\
Negle ct & $17(13 \%)$ & $3(4 \%)$ & $6(18 \%)$ & 0 & 26 \\
Physical & $2(.01 \%)$ & $3(4 \%)$ & $.3(<1 \%)$ & $1(1 \%)$ & 6 \\
\hline
\end{tabular}

Note. Percentages are column specific

Table 2: Total Averaged Number of Abusive Behaviours by Sport

A number of relevant analyses are important to highlight. First, across all sports, indirect coaching abuses $(n=199)$ significantly outnumber direct coaching abuses $(n=56), \chi^{2}(3,255)=.18 .52, p=.000$. Secondly, the two contact sports, hockey and football — when compared to baseball and basketball, which have considerably less physical contact - contain the greatest number of direct abuses $(n=47$ and 9 respectively), $\chi^{2}(1,255)=10.79, p=.001$. Although the numbers are relatively small, the contact sports also contain the greatest number of neglect behaviours $(n=23), \chi^{2}(3,255)=9.27, p=.026$ (two cells had less than 5 behaviours) as compared to the noncontact sports $(n=3)$. Finally, psychological ( 43.5 per cent) and modelling ( 44.7 per cent) behaviours are the greatest percentage of all negative behaviours across all sports.

\section{Discussion}

Despite some warranted concerns regarding the use of surveillance and monitoring in sport due to the potential abuse of power through governance that is facilitated by the knowledge produced by such procedures (Fusco 2009; Lang 2010; Sluggett 2011;), it is conspicuous to note that similar abuses of power occur without evidence, through storylines and paradigms that remain tightly controlled by policy makers (Fischer 2003; McGee and Brock 2001; Stone, Maxwell, and Keating 2001). However, perhaps there is a way for all stakeholders in the youth sport environment to benefit from and direct their own 
learning from the evaluation of the data monitoring programme presented here. It becomes clear that some forms of surveillance are not only warranted but useful. JPBMP uses a form of surveillance that was preexisting, yet unrecognized, in the youth sport context (i.e. official ratings), and uses this system to provide a useful monitoring tool that facilitates the administration and positive development of sports.

The aim of this paper was to present evidence that suggests the surveillance and monitoring of the youth sport environment, with specific regard to coaching behaviours, is warranted and necessary. Despite the acknowledgement from experts that there is a serious lack of positive surveillance, monitoring, and evaluation (Brackenridge 2007; David 2005; UNICEF 2010), especially with regard to violence and abuse in youth sport, which David (2005: 9) calls the 'black hole of data', policy continues to be developed and implemented (Brackenridge 2005). Yet questions remain as to what evidence is used to define the problem of abuse and violence in youth sport, and what indicators have been selected to evaluate outcomes, objectives, goals, and effectiveness of these policies. Although Biglan et al. (2003: 437) are not referring to youth sport, when they state, '(i)f the child-rearing and educational systems are going to come close to the effectiveness of the best manufacturing systems, continuous training and implementation monitoring must become standard practice', this sentiment can also be applied to coaching and youth sport. Those in favour of evidence-based policy management posit that "policy should not be guided by "dogma" but knowledge of "what works and why" (Parsons 2002: 3). Yet it would seem that sport policy has been governed instead by the storylines that perpetuate the power of governing bodies. The evidence provided by the results of this study overwhelmingly affirms that children participating in youth sport programmes are subject to harmful coaching behaviours, alarming in their prevalence and scope.

The classification process utilized in the present study identified 255 behaviours from 164 officials' comments across four different sports, with an average of 198 indirect behaviours ( 77 per cent) and 58 (23 per cent) direct behaviours. Although the numbers vary somewhat from the first classification using the TOCT model (Raakman et al. 2010a), the distribution pattern is very similar. Taken together, these data indicate that children are exposed to negative coaching behaviours within youth sport much more than previously thought. Indeed, the previously suggested incidence of 10 per cent (David 2005) is less than half of the direct abuses identified in this study, and far less than the 18 per cent of direct abuses identified in the first TOCT classification (Raakman et al. 2010a).

The rate of occurrence of negative coaching behaviours is sadly magnified once indirect abuses are factored into the equation. Indirect abuse was a concept identified by Rakman et al. (2010a) during the development of the TOCT model when it became apparent that a large majority of problematic behaviours could not be classified into commonly established categories. Instead of being directed at the children, children experienced these behaviours as unwitting witnesses, iteratively, over the course of their season. Similar to the concept of background anger introduced by Omli and LaVoi (2009), indirect abuse may have serious long-term negative consequences on the psyche of children (Raakman et al. 2010a; Omli and LaVoi 2009). This area of research is limited in the sport setting and definitely needs to be a priority among researchers examining youth sport. The JPBMP provides a means of using positive surveillance and monitoring to promote and simply research in these priority areas.

Importantly, the evaluation of the data discovered by the present research re-emphasizes that the most prevalent types (indirect psychological) of harmful behaviours identified by the monitoring are those that are commonly normalized within the youth sport environment and as such are not recognized as harmful. These include harassing officials, yelling at officials, challenging calls, harmful behaviour, foul language/emotional displays, removal from game, and intimidation. These types of behaviours are considered to be part of the youth sport culture within the CSP framework and were expressed in similar ways across all sports. While behaviours are not unique to a particular sport, it was found that coaches in contact sports were attributed with more direct coaching transgressions than coaches in non-contact sports. Since the CSP framework suggests that behaviours are reinforced and supported by the particular culture, 
it could be that the increased physicality of contact sports legitimizes this type of direct negative coaching behaviour. More research into this area is most certainly necessary and warranted.

It needs to be emphasized that the behaviours examined in this study were those identified by contextual experts within the field of play (i.e. the officials) as unacceptable. So, while the officials are privy to the cultural norms surrounding behaviours within each of the sport subcultures, they deemed these behaviours as 'over the top'. In essence then, the official has always provided surveillance for youth sports, but their surveillance has not been recognized as such, nor utilized to its fullest potential for the benefit of sport. It should also be noted that the data collected by the JPBMP reflects conduct during competition only. It does not, as yet, capture conduct during practice situations, and consequently provides information for just one, albeit important, aspect of the youth sport environment. For this reason, acts considered sexually abusive were not identified, as these typically occur out of the public's scrutiny. Despite this limitation, the behaviours reported using the JPBMP occur during public competition.

It is clear that the data collected from the JPBMP provided critical information that led to the development of the TOCT model (Raakman et al. 2010a), and subsequently key indicators of direct and indirect categories of harmful coaching behaviours and their prevalence. As stated earlier, prevalence is a fundamental factor determining whether or not a problem is deemed important (Biglan, Mrazek and Carnine and Flay 2003) and whether preventative measures should be taken. Biglan et al. (2003: 435) also state:

... the development of monitoring systems represents an important step in the integration of science into society's child-rearing practices. These systems make it possible for individual communities and even neighborhoods to monitor and precisely evaluate the effectiveness of their prevention efforts.

Finally then, the question becomes how the needs of a multiplicity of stakeholders within the youth sport environment can be aligned and best accomplished through surveillance, and consequently, monitoring. In particular, the monitoring of coaching behaviours can help to inform policy development regarding standards of coaching behaviours, as well as coach training and development. Schon (as cited in Parsons 2002) suggested that the best systems provided the means for learning and adaptation at all levels, and allow knowledge to be accessed by everyone, facilitating organizational growth and transformation that is self-directed and collaborative. It is the opinion of the authors that the JPBMP provides such a tool. For example, the JPBMP allows grass-roots sport organizations to learn about and manage their own unique environment, enhancing their abilities to identify and solve their own unique problems, while at the same time it can provide valuable information regarding trends in behaviours to governing bodies. Lyon (2007) also suggests that surveillance is an interactive process, and individuals will engage with and respond more positively to surveillance systems if: (a) they perceive a benefit; (b) they are informed of the surveillance; (c) the sensitivity of data being collected is appreciated and; (d) organizations use the information responsibly. Because the JPBMP provides all three elements of an interactive process, grass roots to national governing bodies using the programme have expressed positive results.

Having a monitoring system such as JPBMP in place, providing real-time data on key indicators and provided by members of the specific subculture (namely the officials), fills a gap that has been clearly acknowledged in a simple and efficient manner. It is also evidence of the benefits provided by positive surveillance. Although the low number of comments for two of the sports in particular, football and baseball, is a serious concern, it is hoped that the results discovered here serve to inspire future etic hypotheses, and highlight the usefulness of positive surveillance and need for monitoring of youth sports in order to produce, inform, and evaluate policy that protects the rights of children - and de-mythologize sport. 


\section{Acknowledgements}

The authors would like to thank all of the officials who participated in this study and their respective sport organizations for their diligence in trying to make the sport experience for youth participating under their care a positive one. This research was conducted as a portion of the master's thesis of the first author, Elaine Cook (formerly Raakman). Correspondence concerning this article can be directed to Dr. Kim Dorsch, Motivation for Active Living Laboratory, Faculty of Kinesiology and Health Studies, University of Regina, Regina, SK, Canada. Email contact: Kim.Dorsch@uregina.ca

\section{References}

Abraham, A., D. Collins and R. Martindale. 2006. The Coaching Schematic: Validation Through Expert Coach Consensus. Journal of Sports Science 24(6): 549-564.

Baker, J., J. Yardley and J. Côté. 2003. Coach Behaviours and Athlete Satisfaction in Team and Individual Sports. International Journal of Sport Psychology 34: 226-239.

Barnett, N.P., F.L. Smoll and R.E. Smith. 1992. Effects of Enhancing Coach-Athlete Relationships on Youth Sport Attrition. The Sport Psychologist 6: 111-127.

Beyond Sport Summit. July 25-27, 2012. London, United Kingdom.

Biglan, A., P.J. Mrazek, D. Carnine and B.R. Flay. 2003. The Integration of Research and Practice in the Prevention of Youth Problem Behaviours. American Psychologist 58: 433-440.

Bolter, N. 2010. Coaching For Character: Mechanisms of Influence on Adolescent Athletes' Sportsmanship. PhD diss., Accessed December 12, 2011. http://conservancy.umn.edu/bitstream/.../1/Bolter_umn_0130E_11394.pdf.

Brackenridge, C. 2004. Burden or Benefit? The Impact of SportScotland's Child Protection Programme with Governing Bodies of Sport. Research Report 94, Edinburgh: SportScotland.

Brackenridge, C. 2006. Women and Children First? Child Abuse and Child Protection in Sport. In: Sport, Civil Liberties and Human Rights, eds R. Giulianotti and D. McArdle, 30-45. New York: Routledge.

Brackenridge, C. 2007. Violence and Abuse Prevention in Sport. In: The Prevention of Sexual Violence: A Practitioner's Sourcebook, ed. K. Kaufman. Fitchburg, MA: Neari Press.

Brackenridge, C. 2012. Managing Research on Violence to Children in Sport. In: Sport, Children's Rights and Violence Prevention: A Sourcebook on Global Issues and Local Programmes, eds C. Brackenridge, T. Kay and D. Rhind, 54-61. London: Brunel University Press.

Brackenridge, C., J. Bringer and D. Bishopp. 2005. Managing Cases of Abuse in Sport. Child Abuse Review 14: $259-274$.

Brackenridge, C. and K. Fasting. 2009. Coaches, Sexual Harassment and Education. Sport Education and Society 14(1): 21-35.

Brackenridge, C., T. Kay and D. Rhind. 2012. Sport, Children's Rights and Violence Prevention: Sport, Children's Rights. London: Brunel University Press.

Brackenridge, C., Z. Pawlaczek, J. Bringer, C. Cockburn, G. Nutt, A. Pitchford and K. Russell. 2005. Measuring the impact of child protection through Activation States. Sport, Education and Society. 10 (2): 239-256.

Brackenridge, C. and D. Rhind. 2010. Elite Child Athlete Welfare: International Perspectives. London: Brunel University Press.

Chapman, G. 1997. Making Weight: Lightweight Rowing, Technologies of Power, and Technologies of the Body. Journal of sport and social issues 17 (2): 77-97.

Child Protection in Sport Unit (CPSU). 2003. Standards for Safeguarding and Protecting Children in Sport. Child Protection in Sport Unit: Leicester.

Coalter, F. 2007. A Wider Social Role for Sport-Who's Keeping the Score? London: Routledge.

Cohen, M.A. 1999. Monitoring and Enforcement of Environmental Policy. In: International Yearbook of Environmenal and Resource Economics, eds T. Tietenberg and H. Foler. Vol. III. Edward Elgar.

Cummings, E.M. 1987. Coping with Background Anger in Early Childhood. Child Development 58: 976-984.

David, P. 2005. Human Rights in Youth Sports: A Critical Review of Children's Rights in Competitive Sports. New York: Routledge.

Dorsch, K.D., H.A. Riemer, J. Zimmer and E. Karreman. 2009. Coaches' Character Building Efficacy: Are They as Good as They Believe? Paper presented at the Petro-Canada Sport Leadership sportif 2009 and the International Council for Coach Education/Canadian Coaching Association Global Coach Conference, Vancouver, BC, November.

Dunn, W. 2008. Public policy analysis: An introduction (4 ${ }^{\text {th }}$ ed.). New Jersey: Pearson Prentice Hill.

Duffy, P. 2010. Ethics in Sport Coaching. Bulletin 58: 12-18.

Fasting, K., C. Brackenridge and J. Sundgot-Borgen. 2004. Prevalence of Sexual Harassment Among Norwegian Female Elite Athletes in Relation to Sport Type. International Review for the Sociology of Sport 39(4): 373-386.

Fischer, F. 2003. Reframing Public Policy: Discursive Politics and Deliberative Practices. Oxford: Oxford University Press.

Forster, J. 2006. Global Sports Organizations and Their Governance. Corporate Governance 6(1): 72-83.

Fung, L. 2003. Assessment: Coaching Efficacy as Indicators of Coach Education Program Needs. Athletic Insight 5(1): $12-18$.

Fusco, C. 2009. Subjection, Surveillance, and the Place(s) of Performance: The Discursive Productions of Space in Canada's National Sport Centre Policy. Sport History Review 40: 1-29.

Gervis, M. 2010. From Concept to Model: A New Theoretical Framework to Understand the Process of Emotional Abuse in Elite Child Sport. In: Elite Child Athlete Welfare: International Perspectives, eds C. Brackenridge and D. Rhind, 60-69. Uxbridge, UK: Brunel University Press. 
Gervis, M. 2012. Child Athletes' Negative Emotional Responses to Their Coaches in the United Kingdom. In: Sport, Children's Rights and Violence Prevention: A Source Book on Global Issues and Local Programmes, eds C. Brackenridge, T. Kay and D. Rhind, 154-159. Uxbridge, UK: Brunel University Press.

Gervis, M. and N. Dunn. 2004. The Emotional Abuse of Elite Child Athletes by Their Coaches. Child Abuse Review 13: $215-223$.

Gibbons, S.L., V. Ebbeck and M.R. Weiss. 1995. Fair-Play for Kids: Effects on the Moral Functioning of Children in Physical Education. Research Quarterly for Exercise and Sport 66: 247-255.

Giulianotti, R. 2004. Human rights, globalization and sentimental education: The case of sport. Sport in Society 7(3): 355-69.

Gould, D. and S. Carson. 2008. Life Skills Development Through Sport: Current Status and Future Directions. International Review of Sport \& Exercise Psychology 1(1): 58-78.

Hall, P. 1990. Policy Paradigms, Experts and the State: The Case of Macro-economic Policy Making in Britain. In: Social Scientists, Policy and the State, eds S. Brooks and A. Gagnon, 53-79. New York: Praeger.

Hallgren, K. 2012. Computing Inter-Rater Reliability for Observational Data: An Overview and Tutorial. Tutorials in Quantitative Methods for Psychology 8(1): 23-24.

Houlihan, B., D. Bloyce and A. Smith. 2011. Developing the Research Agenda in Sport Policy. International Journal of Sport Policy and Politics 1(1): 1-12.

International Council for Coach Education (ICCE). 2010. Building the Coaching Community Across the Globe. Accessed December, 2011. http://www.icce.ws/

Johns, D.P. and J.S. Johns. 2000. Surveillance, Subjectivism and Technologies of Power. International Review for the Sociology of Sport 35 (2): 219-234.

Kusek, J. and R. Rist. 2008. Ten Steps to a Results Based Monitoring and Evaluation System. In: Bridging the Gap, ed. M. Segone, 98-117. Geneva, Switzerland: UNICEF.

Lang, M. 2010. Surveillance and Conformity in Competitive Youth Swimming. Sport, Education and Society 15 (1): $19-37$.

LaPorte, R., H. Kohl, S. Dearwater, A. Kriska, R. Anderson, D. Aaron, T. Olsen and D. McCarty. 1993. Surveillance of Serious Recreational Injuries: a Capture-Recapture Approach. Medicine and Science in Sports and Exercise: 204-209.

Lett, J. 2012. Emic Etic Distinctions. Accessed $\quad$ September $24, \quad 2012$. http://faculty.ircc.cc.fl.us/faculty/jlett/Article\%20on\%20Emics\%20and\%20Etics.htm.

Light, R.J. 1971. Measures of Response Agreement for Qualitative Data: Some Generalizations and Alternatives. Psychological bulletin 76(5): 365-377.

Lyon, D. 2007. Surveillance, Power and Everyday Life. In: The Oxford Handbook of Information and Communication eds R. Mansell, C. Avgerou, D. Quah and R. Silverstone, 449-472. New York: Oxford University Press.

Maguire, J. and L. Mansfield. 1998. No body's perfect: women, aerobics and the body beautiful. Sociology of sport journal 15 (2): 109-137.

Malkin, K., L. Johnston and C. Brackenridge. 2000. A Critical Evaluation of Training Needs for Child Protection in UK Sport. Managing Leisure 5: 151-160.

Mallett, C. and J. Côté. 2006. Beyond Winning and Losing: Guidelines for Evaluating High Performance Coaches. The Sport Psychologist 20(2): 213-221.

McCallister, S.G., E.M. Binde and M. Weiss. 2000. Teaching Values and Implementing Philosophies: Dilemmas of the Youth Sport Coach. Physical Educator 57(1): 35-46.

McGee, R. and K. Brock. 2001. From Poverty Assessment to Policy Change: Processes, Actors and Data (Working paper 133). Brighton, England: Institute of Development Studies.

Omli, J. and N.M. LaVoi. 2009. Background Anger in Youth Sport: A Perfect Storm? Journal of Sport Behavior 32(2): $242-260$.

Parsons, W. 2002. From Muddling Through to Muddling Up - Evidence Based Policy Making and the Modernisation of British Government. Public Policy and Administration 17(3): 43-60.

Patton, M. 2001. Evaluation, Knowledge Management, Best Practices and High Quality Lesson Learned. American Journal of Evaluation 22: 229-336.

Pintér, L., D. Swanson and J.E. Barr. 2004. Use of Indicators in Policy Analysis. Annotated Training Module Prepared for the World Bank Institute. Winnipeg, Canada: International Institute for Sustainable Development.

Raakman, E. 2006. Justplay: A Revolutionary Approach to Youth Sport Administration and Sportsmanship. Journal of Physical Education, Recreation and Dance 77: 20-24.

Raakman, E., K.D. Dorsch and D. Rhind. 2010a. The development of a typology of abusive coaching behaviours within youth sport. International Journal of Sports Science and Coaching 5(4): 503-15.

Raakman, E., K.D. Dorsch and D. Rhind. 2010b. A Critical Review of Coach Conduct Using a Human Rights in Sport Model. The Bulletin 58: 26-28.

Rutten, E.A., J.M.G.J. Stams, G.J.J. Biesta, C. Schuengel, E. Dirks and J. Hoeksma. 2007. The Contribution of Organized Youth Sport to Antisocial and Prosocial Behaviour in Adolescent Athletes. Journal of Youth Adolescence 36: 255-264.

Sandberg, J. 2005. How Do We Justify Knowledge Produced Within Interpretive Approaches? Organizational Research Methods 8: 41-68.

Shields, D., N. LaVoi, B. Bredemeier and F.C. Power. 2007. Predictors of Poor Sportspersonship in Youth Sports: Personal Attitudes and Social Influences. Journal of Sport \& Exercise Psychology 29(6): 747-762.

Shields, D.L., B.L. Bredemeier, N.M. LaVoi and F.C. Power. 2005. The Sport Behaviour of Youth, Parents, and Coaches: The Good, the Bad, and the Ugly. Journal of Research in Character Education 3: 43-59.

Sluggett, B. 2011. Sport's Doping Game : Surveillance in the Biotech Age. Sociology of Sport Journal: $387-403$. 
Smith, R.E., F.L. Smoll and S.P. Cumming. 2007. Effects of a Motivational Climate Intervention for Coaches on Young Athletes' Sport Performance Anxiety. Journal of Sport and Exercise Psychology 29(1): 39-59.

Steelman, T. 1995. Enhancing the Youth Sports Experience Through Coaching. Parks and Recreation 29(11): 14-17.

Stem, C., R. Margoluis, N. Salafsky and M. Brown. 2005. Monitoring and Evaluation in Conservation: A Review of Trends and Approaches. Conservation Biology 2: 295-309.

Stirling, A. 2008. Definition and Constituents of Maltreatment in Sport: Establishing a Conceptual Framework for Research Practitioners. British Journal of Sport Medicine Online. 2009;43:1091-1099. Accessed: August 2013. doi:10.1136/bjsm.2008.051433.

Stirling, A.E. and G.A. Kerr. 2007. Abuse in Special Populations. Journal of Emotional Abuse 7(4): 89-113.

Stone, D., S. Maxwell and M. Keating. 2001. Bridging Research and Policy. Paper presented at the International Workshop funded by the UK Department for International Development, Radcliffe House, Warwick University, July, 16-17.

Telfer, H. 2012. Proactive practice: Coaching children and young people. In" Sport, Children's Rights and Violence Prevention: A Sourcebook on Global Issues and Local Programmes, eds by C. Brackenridge, T. Kay and D. Rhind, 54-61. London: Brunel University Press.

Turner, M. and P. McCrory. 2004. Child Protection in Sport. British Journal of Sports Medicine 38: 106-107.

UNICEF, Innocenti Research Centre. 2010. Protecting Children from Violence in Sport. A Review with a Focus on Industrialized Countries. Florence (Italy): Author.

Walters, S., P. Schluter, R. Thomson and D. Payne. 2011. The Effects of Adult Involvement on Children Participating in Organized Team Sports. PhD diss., Accessed, October, 23, 2011. http://aut.researchgateway.ac.nz/handle/10292/2415.

Weber, R. 2009. Protection of Children in Competitive Sport: Some Critical Questions for London 2012. International Review for the Sociology of Sport 44(55): 55-69.

Whitehead, T. 2005. Basic Classical Ethnographic Research Methods Secondary Data Analysis, Fieldwork, Observation/Participant Observation, and Informal and Semi-structured Interviewing. Ethnographically informed community and cultural assessment research systems (EICCARS) working paper series. http://www.cusag.umd.edu/documents/WorkingPapers/ClassicalEthnoMethods.pdf 